\title{
Management of Risk in Engineering: Risk Allocation through Contractual Approaches
}

\author{
by R.W. Hayes*
}

\begin{abstract}
This paper considers the case study of a turnkey project bid as presented by Chapman and Cooper. It examines the risks as perceived by the contractor, and considers how alternative forms of contract may have re-allocated the risks in such a manner as to encourage the contractor to submit a tender price for the project.
\end{abstract}

\section{Introduction}

Chapman and Cooper (1) provided details of a risk analysis for a thermal power project in the Middle East. The analysis was undertaken because of the recognition by the contractor that this was a high risk project - risk which was increased for the contractor by the client's insistence on a fixed price turnkey contract.

The analysis led to a decision by the contractor not to tender for the work. As he was a favoured bidder, this was presumably not the desired outcome for the client. This short paper examines the risks as they may have been perceived by the contractor, and seeks to demonstrate how other contractual arrangements may have resulted in a more equitable sharing of the risk and a willingness by the contractor to tender for the contract.

\section{The contractor's perception}

Any major project of this type will have risks associated with it - risks which are increased for the contractor when the project is overseas. Additionally, the use of a turnkey contract gives the client the opportunity to place all the risk for construction, financing and delay onto the contractor, and means that any price quoted is necessarily based on assumptions involving considerable uncertainty.

* B. Sc., M. Sc., MICE Senior Research Assistant, Project Management Group, Department of Civil Engineering, UMIST, the University of Manchester Institute of Science and Technology; paper presented to the Third Seminar of the Management of Engineering Group, sponsored by the Geneva Association, 17-19 April, 1985. 
The use of a turnkey contract does not demand that the client removes himself from all the risk, but it does give him the opportunity to do so. The precise wording of the contract terms in ostensibly similar contracts can produce very considerable differences in the client/ contractor risks and relationships. For example, similar turnkey contracts may either leave all the risk of inflation with the contractor or suggest limits beyond which the client deems that inflation is out of the contractor's control and cost.

In this example the contractor assumed a harsh scenario in his analysis of risk - that of a client wishing to accept no risk. Four major areas of risk were identified:

a) Time - delay during construction;

- client delay in signing the contract.

b) Base cost estimating error by the contractor.

c) High rates of inflation.

d) Cash flow - low return on fee advances;

- uncertain value of fee advances;

- uncertain payment by client.

The contractor adopted an adversarial approach to any risk situation by concentrating on the financial and legal implications of the contract. Little room was left for management responses to risk involving trade-offs appropriate to both the contractor and client, for this form of contract, if rigidly applied, leaves little possibility of negotiation and a client/contractor team approach.

\section{The client's perception}

The client chose to use a turnkey approach. Such an approach is likely to lead to the following results:

a) Lower perceived risk to the client.

b) Minimum client management resources.

c) High risk contingencies by the contractor

or: High risk exposure for the contractor

or: No acceptable offer to construct by the contractor.

The client's selection of contractual approach led to a negative bid response from the contractor. However, the client did have the choice of many other approaches (see figure 1). This choice should be the result of an effective and early consideration of contract strategy, and an appraisal of all the risks and contractual responses.

Two other contractual approaches - Target Cost and Management Contracting - are common on overseas projects; and could have been considered here. However, both demand from the client a willingness to negotiate, a willingness to share the risks, and a willingness to act in collaborative teamwork with the contractor. 


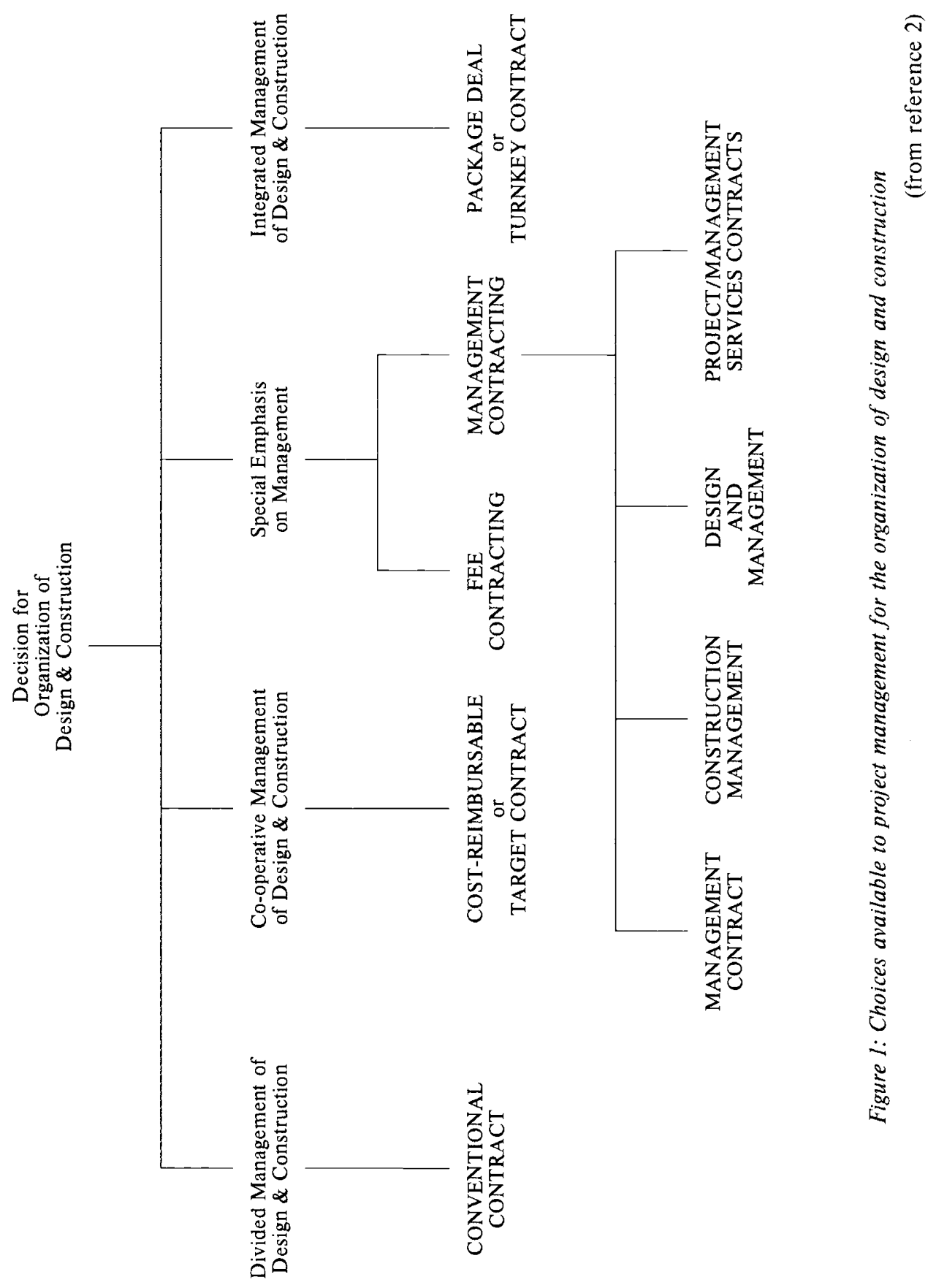




\section{Target cost contracts}

In a target cost contract, the contractor will still take responsibility for the construction, and the design if this has been placed in his contract. The construction work is reimbursed at actual cost, the contractor is paid an agreed tendered management fee, and the target cost is adjusted as necessary during the duration of the project. A proportion of the difference between the target and actual final cost is paid to or paid by the contractor. Changes to the project specification are easier to accommodate, but they do require changes to the target cost. In consequence clear communication between the client and the contractor is always needed, and a close working relationship is required.

Table l gives a list of the main circumstances favouring the use of a target contract. References 3 and 4 give greater details of such contracts.

The risk assessment and allocation in this arrangement is considerably different. The risk of client delay before signing is reduced for the contractor, since the target can be re-adjusted to accommodate inflation. The contractor may still have problems with the re-allocation of resources if delay does occur, but his cash flow problems are reduced by the use of a reimbursable approach (see figure 2 for a typical cash flow curve) and much of the the risk in estimating portfolio investments is removed.

Table 1: Circumstances favouring the use of Target Cost Contracts

(from reference 4)

1. Inadequate definition of work at time of tender.

2. Work is technically or organizationally complex.

3. Design input from contractor is desirable.

4. Situations involving major unquantifiable risks for the contractor.

5. Client wishes to be involved in the management of his project.

Table 2: Circumstances favouring the use of Management Contracting

(from references 5)

1. Need for an early start.

2. Need for an early completion.

3. Need to consider particular construction methods.

4. Need for flexibility for change.

5. Organizationally complex project.

6. Client and his advisers have insufficient management resources.

7. Special labour requirements - for example, the use of local labour. 


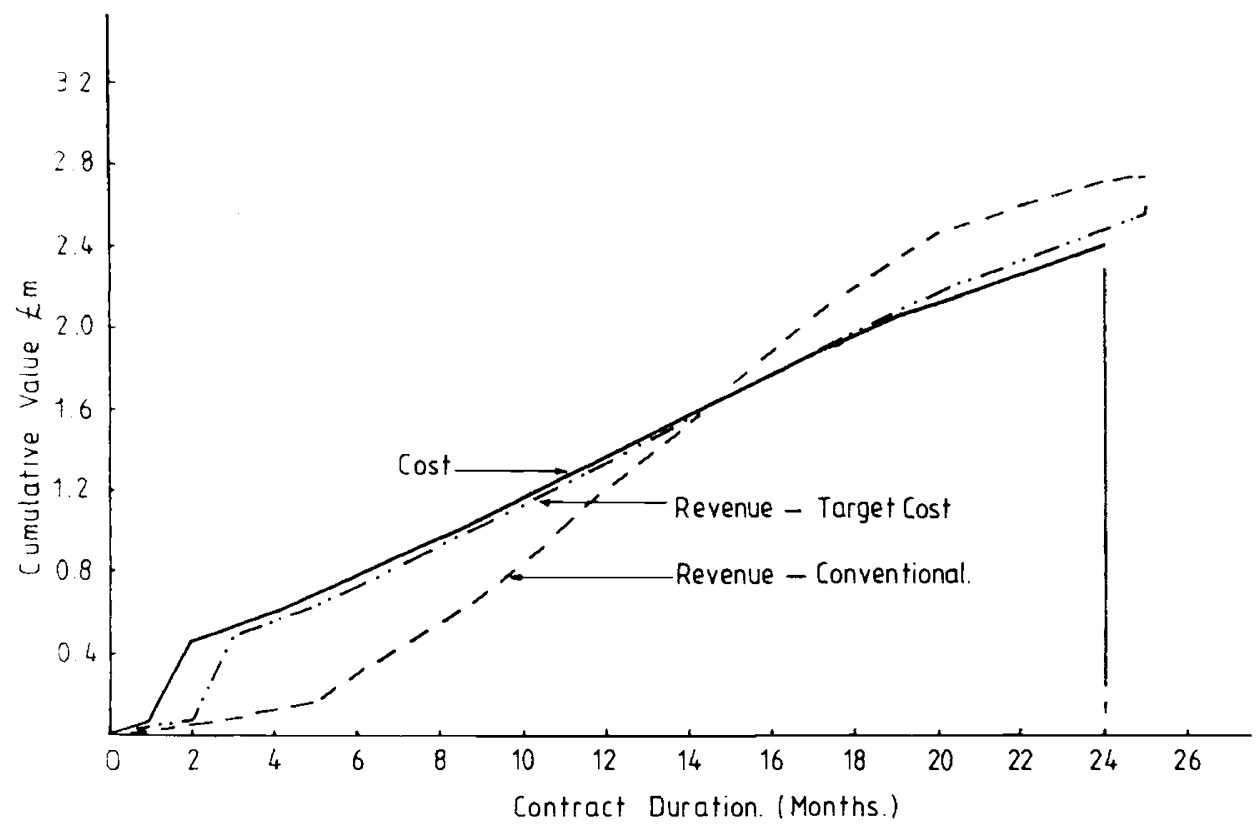

Figure 2: Typical comparative cash flows for conventional and target cost contracts

Base cost estimating error remains a risk for the contractor in that his ability to achieve the target cost may be affected. Errors which can be shown to be client induced will cause an adjustment to the target.

\section{Management contracting}

Table 2 gives circumstances identified in a recent study (5) favouring the use of management contracting. Figures 3 and 4 show typical organizational and contractual structures. As can be seen, these structures are considerably different from the conventional, turnkey, or even target approaches. The management contractor is no longer doing any of the construction himself, and is accepting little of the construction risk. Those risks which cannot be passed to the individual package construction contractors will be retained by the client.

The risk of delay is reduced. For the management contractor a delay in signing the contract has little financial effect since he is paid actual cost plus a fee. For the client, any delay occurring during the construction phase can often be overcome by recourse to "fast-tracking" - overlapping design and construction: a frequent emphasis in this form of contract.

Further, the process of parcelling the construction into individual packages, to be let as and when necessary, allows the client the freedom to adjust the rate of work. One benefit of this approach is that the client can adjust construction to suit his own financial obligations and availability of funds, so reducing the risk of cash flow problems for the constructors because of delayed payments. 


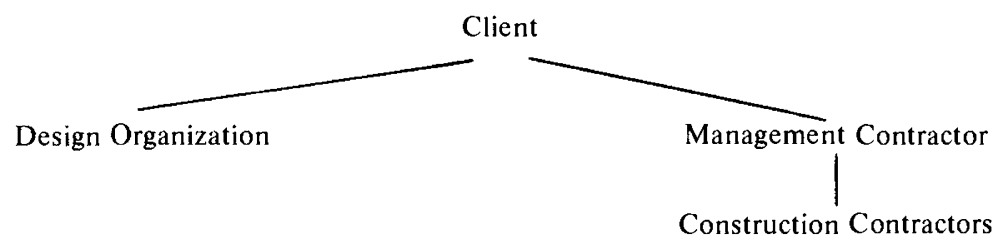

Contractual

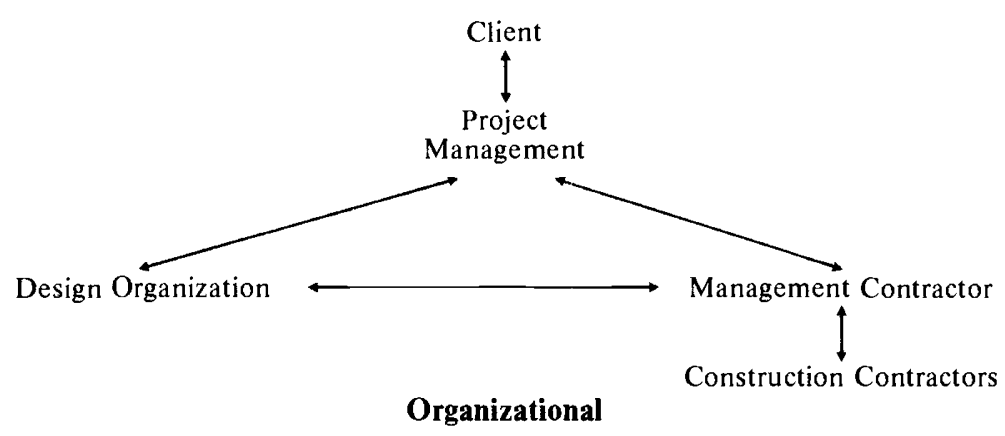

Figure 3: The management contract: contractual and organizational relationships

(from reference 2)

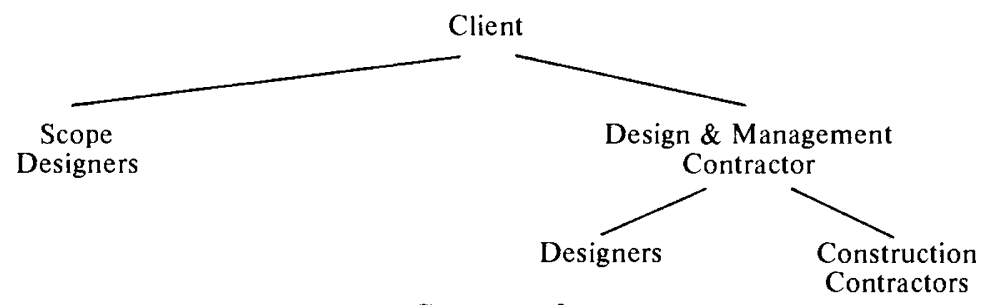

\section{Contractual}

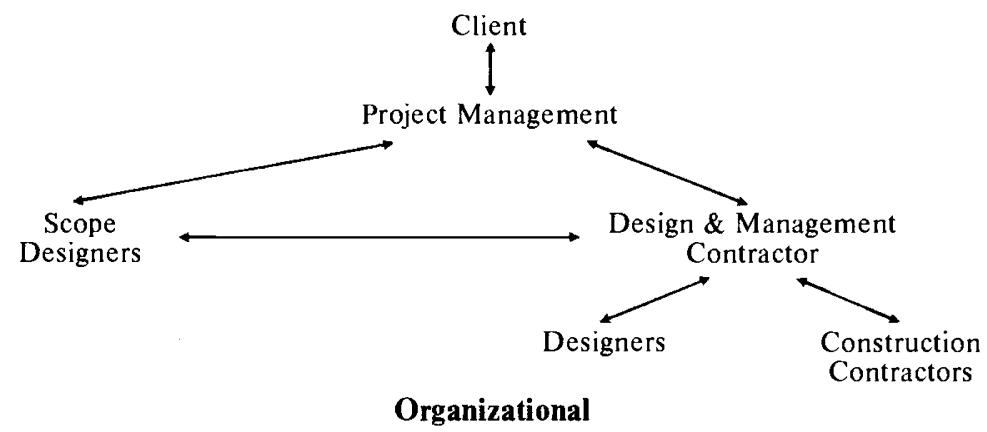

Figure 4: The design and management contract: contractual and organizational relationships

(from reference 2) 
The management contractor loses the opportunity of a large windfall profit - but does have a guaranteed return. The client loses the protection (if such exists) of an initial guaranteed price - but does not pay large contingency sums for risks which may never happen.

\section{Conclusions}

Chapman and Cooper (1) discussed an analysis which resulted in a situation where the contractor was not prepared to tender.

For any project which falls into the categories listed in eitherTable 1 or 2 , the adoption of a turnkey approach may frequently give this result. Either of the two other approaches discussed above demand a different attitude on the part of the client. They require a willingness by the client to accept more of the direct risks himself, to be prepared to work more closely with the contractor, and to provide more of his own managerial expertise. However, this difference in attitude can have significant advantages.

For this particular case, an early contract strategy appraisal may well have suggested that target or management contracting was a more realistic approach. Either form may have allowed some of the risks to be minimised through management decisions within the contractual framework. One clear conclusion is that the allocation of risk in a project is strongly influenced by the contractual arrangement adopted, and that this should be recognised and accommodated in the early contract strategy stage.

\section{REFERENCES}

1. CHAPMAN, C.B. and COOPER, D.F.: "Contract risk analysis for a turnkey project bid: a case study", published with this paper.

2. HAYES, R.W.: "A study of management contracts", M.Sc. thesis, University of Manchester, UMIST, 1983.

3. PERRY, J.G., THOMPSON, P.A. and WRIGHT, M.: "Target and cost-reimbursable construction contracts", Parts A, B and C, CIRIA Report 85, London, 1982.

4. PERRY, J.G.: "The development of contract strategies for construction projects", Ph.D. thesis, University of Manchester, UMIST, 1985.

5. HAYES, R.W., PERRY, J.G. and THOMPSON, P.A.: "Management contracting", CIRIA Report 100, London, 1983. 